\title{
Information and Communication Technology (ICT) and the Agroecological Transition
}

\author{
Lola Leveau, Aurélien Bénel, Jean-Pierre Cahier, François Pinet, \\ Pascal Salembier, Vincent Soulignac, and Jacques-Eric Bergez
}

\begin{abstract}
The development of information and communication technologies (ICT) has to meet the needs of farmers and sustainably support the competitiveness of agriculture in a rapidly changing digital world. Under certain conditions of use, digital tools could facilitate the application to agriculture of the historical, methodological and socio-economic principles defining agroecology. This chapter is composed of four sections. In the first section we define a framework to study agricultural IC tools. The second section considers how ICT should be used during the design phase of the territorial agroecological transition - an example of which is the TATABOX project -, before its actual implementation. The third section sets out the four types of IC tools that can usefully be applied during this transition, and provides several examples. Finally, the last section shows the various barriers that ICT specialists will have to overcome in order to provide effective support to food systems. It also discusses the contradiction that can exist between high energy-consuming technologies and an agroecological production paradigm in which a drastic reduction of the reliance on fossil energy is essential.
\end{abstract}

L. Leveau $(\varangle) \cdot$ F. Pinet $\cdot$ V. Soulignac

TSCF, Irstea, Centre de Clermont-Ferrand, Aubière, France

e-mail: lola.leveau@gmail.com; francois.pinet@irstea.fr; vincent.soulignac@irstea.fr

\footnotetext{
A. Bénel · J.-P. Cahier · P. Salembier

Institut Charles Delaunay -TechCICO, Université de Technologie de Troyes, Troyes, France e-mail: aurelien.benel@utt.fr; jean-pierre.cahier@utt.fr; pascal.salembier@utt.fr

\section{J.-E. Bergez}

AGIR, Université de Toulouse, INRA, Castanet-Tolosan, France

e-mail: jacques-eric.bergez@inra.fr
} 


\section{Introduction}

The numbers of Information and Communication Technologies (ICT) available are constantly increasing, and so are their applications in the agricultural sector. As explained in the French ICT \#DigitAg project ${ }^{1}$ reference text, "Digital agriculture may have started more than 40 years ago, with the first civil satellite programmes enabling earth remote sensing, followed by the computer capacity boom in the $80 \mathrm{~s}$, which made it possible to digitalise crop models, to build expert systems and to introduce precision agriculture. Subsequent technological breakthroughs produced mobile phones and smartphones, satellite communications, GPS, more accessible wide-ranged satellite data, and now connected objects and Internet of things. Agricultural engineering research has benefited from these offers. Concerning sensors, research has been dedicated to exploiting satellite images, developing new sensing techniques for specific properties (e.g. quality, disease). The latest developments are in wireless sensor networks in fields, and in phenotyping, as the lack of phenotyping sensors is a bottleneck of genomic research." (\#DigitAg 2017).

Under certain conditions of use, digital tools could facilitate the application of the historical, methodological and socio-economic principles defining agroecology as conceptualized by Altieri, the SAD department of INRA or the GIRAF group (Stassart et al. 2012). For example, ICT could support the development of multicriteria guidance for agro-ecosystems, the construction of participatory research frameworks, the creation of networks promoting public debate and knowledge diffusion, and the re-localisation and co-management of food systems by both producers and citizen-consumers. It could moreover highlight the diverse forms of knowledge to take into account in the construction of a problem and the research contributions to solving it.

In this chapter, we discuss this issue of ICT's role in agroecology: are the different IC tools parts of the game and how can they be used to facilitate the agroecological transition (AET) of a territory? The chapter is composed of four sections. In the first section we define a framework to study agricultural IC tools. The second section considers how ICT should be used during the conception phase of the territorial AET - an example of which is the TATA-BOX project -, before its actual implementation. The third section sets out the four types of IC tools that can usefully be applied during the practical implementation of this transition, and provides several examples. Finally, the last section shows the various barriers that ICT specialists will have to overcome in order to provide effective support to food systems, and

\footnotetext{
${ }^{1}$ \#DigitAG is a French research coordination in which 360 scientists are working on digital agriculture, new digital tools and services for the agriculture of the future. Sensors, connected objects, smartphones, satellite images, drones, Internet of Things, big data, high-performance computing systems, as well as decision support, territorial management, frugal innovation, ethics, confidentiality, and management are some of the keywords to meet the challenges of food security and sustainable development. The main goal is to develop information and communication technologies (ICT) to meet the needs of farmers and sustainably support the competitiveness of agriculture in a rapidly changing digital world (http://www.hdigitag.fr/fr/)
} 
discusses the contradiction that can exist between high energy-consuming technologies and an agroecological production paradigm based on fossil resources sobriety (Altieri 1995).

\section{Setting the Framework}

\section{ICT: Support or Slave?}

A big issue when dealing with connected agriculture is how it is defined: either as a model or as a tool for agriculture. This positioning is critical to understand antagonisms, complementarities and utilities in digital agriculture with regard to agroecology.

- If connected agriculture is considered to be a new model of agriculture, it raises fundamental questions about the positioning of this model in relation to other agricultural models, and in particular to agroecological agriculture. This new mainstream digital model imposes on farmers and society a techno-centric point of view which may not be compatible with the principles of agroecological agriculture. In this connected agriculture configuration, there is a risk of transforming agroecological agriculture into techno-centric precision agriculture, transforming biological regulation and knowledge networks into ICT fullyequipped agriculture seeking optimisation at all costs. The solutions here stem from a new top-down approach, placing the sacrosanct trilogy "Certified Seeds, Fertilization, Phytosanitary Coverage" into a new form of dependence on technologies owned by multinational firms. The implications of the change of localterritorial scale, fundamental to the agroecological agriculture approach, are revisited here from the perspective of a territory connected by multiple sensors. Additionally, although the governance of agriculture and its data is still to be imagined, it could easily escape from the farmers' control.

- If connected agriculture is seen as a tool for agriculture, it could constitute a valuable opportunity to objectify agroecological agriculture by providing technologies for better qualifying it and sharing it (Bergez et al. 2016). Through the use of multiple data in predictive models, a connected agriculture with moderate instrumentation could support complex agroecological farming systems by offering coherent decision-making alternatives for innovative practices. It also could provide a geo-localisation of biological phenomena (species, pests, crops, soil type, etc.), allowing differentiated reasoning practices. In addition to this better understanding of biological processes, other IC tools could allow voluntary and chosen knowledge to be shared between stakeholders for better farm and territory management. Connected agriculture could also be seen as a vector for networking in agroecological agriculture, between farmers, between farmers and society (citizen, industry), and between farmers and researchers. 
In this chapter, like Therond et al. (2017), we consider ICT not as underpinning any one agricultural model, but as a range of tools that are usefully applied to various agricultural models. In agroecological agriculture, ICT can be used to support the application of its different principles without distorting them, and without taking the decision-making power away from the farmers. The main issue is then to define the specific ICT needs of agroecological agriculture.

\section{From the Conception to the Practical Implementation of a Transition}

The TATA-BOX project focused on the primary step of an AET: the design, by the local actors, of both a desirable territorial agroecological system (TAES) and the pathway to reach it i.e. the transition to the TAES (tTAES). The methodology developed to conceive this agroecological system was mainly based on face-to-face discussions and "low tech" devices (paper maps, post-it notes, audio recordings, etc.). Some software tools could nevertheless be used to optimise the interactions during future applications of the methodology (Cahier et al. 2016). This postulate will be discussed in section "ICT recommendations to support the conception of a transition: objectives and architectural guidelines" of this chapter.

Apart from the IC tools that are useful during the design of a territorial agroecological system, we decided to widen the scope of this chapter to the digital technologies that could be used during the practical implementation of the designed system. Although these tools are not used during the stages studied by the TATA-BOX project, being aware of their existence while designing a desirable transition path can support choices that differ from a conception process based on the assumption that ICT will not be part of the game. For example, communication tools are interesting to discuss here since communication between people that do not usually work together was an important stake to maintain the momentum created by the project. The IC tools that are useful to a practical agroecological system implementation will be presented in section "ICT to support the implementation of a territorial agroecological transition".

\section{From a Connected Farm to a Connected Food System}

An agroecological transition concerns not only a farming system, but also the whole food system (sensu lato) of which it is part (from farm to table), as well as its relationship with society (Stassart et al. 2012; Duru et al. 2015a, b). The TATA-BOX project, which brought together a wide range of stakeholders from the territorial food systems it studied, is a good illustration of the importance of taking these multiple dimensions into account in order to identify all the mechanisms involved, their 
interdependences, and the obstacle or stepping stone they could represent during the transition. We have therefore chosen not to present IC tools specially conceived for a "connected farm" or for a "connected research laboratory", but rather IC tools that create networks between the actors of a food system, linking farmers to farmers, farmers to researchers, researchers to policy makers or technical advisers, farmers to consumers, and so on.

ICT moreover naturally break down the spatial and temporal boundaries characterizing agriculture, allowing interaction between actors and comparison between situations that would not have happened without them. Consequently, even if we focus on the territorial scale, some technologies will first be described at a larger spatial level so that their local consequences can be explained.

\section{ICT Recommendations to Support the Conception of a Transition: Objectives and Architectural Guidelines}

Based on the TATA-BOX Aveyron meetings, we propose in this section an outline of an ICT platform, combining several IC tools to support the practices of a tTAES. We call a TPD community (agroecological Transition with Participatory Design) any local group engaged in a tTAES. A TPD community is thus to be understood as a complex multirole community, including local stakeholders as well as facilitators, analysts and all the other roles necessary for the successful design of the tTAES. A TPD community, like many communities of practice or communities of action (Wenger 1998; Zacklad 2005; Warner 2006), needs to grow and develop, to describe and organise itself in terms of roles for collaborative work (Herrmann et al. 2004), and constantly to modify content shared among members. In terms of task organisation, the TATA-BOX method involves multiple roles, and an ICT platform must provide an infrastructure for a community portal that accommodates each of them. Each role is endowed with different prerogatives and possibilities of action on the contents.

The main purpose of the platform we propose is to make available to this community the informational content that it consults, creates and modifies through its discussions during the design process. These content-related services are intended to facilitate this provision by respecting the division of labour and confidence requirements necessary for the community design of the tTAES.

In terms of trust and security, an ICT TPD community in a given territory must protect its contents and retain complete control over them. As the technical underlying framework is constituted by Web technologies, the Community needs to have strong fence and effective confidentiality throughout its design and discussion work on the options, verbatim records and content that it develops, annotates and evaluates through the platform. This is particularly important to promote free expression of views internally at design meetings. Within this framework, the digital services 
of the platform, set out below, are essentially intended to serve the constitution, collective manipulation, and "capitalizing" of the traces of design discussions.

Proposed as a foundation for building and supporting socio-technical community systems in the particular TPD field, the platform has to be open and modular, and to avoid structuring too much of the TPD community's activity. In fact, the TATABOX method aims to stay within the frameworks to which rural actors are accustomed, without upsetting them. It incorporates the possibility that, from one TPD community to another, the conditions of the territory, as well as many human or material factors of participatory work, may influence its implementation. A digital platform must therefore adapt to local cultures and constraints, while in each case providing the different TATA-BOX roles with the best opportunities for interaction around shared content.

Technically, the core of the targeted platform is a documentary system based on Web technologies and supported by "Web Services" technologies. In addition to the flexibility of adaptation, the most important expected functionalities considered during the TATA-BOX design process were: supporting a large number and diversity of participants (present or distant); reducing costs and the number of staff involved in organising and running these workshops; ensuring the efficiency and semantic neutrality of the content tracking system; ensuring the simplicity of implementation; and facilitating appropriation of all the roles involved.

Based on these criteria, we recommend an open infrastructure, of the Social Semantic Web type, capable of easily and flexibly hosting the documentary system and these services. The services are illustrated below, in order of priority, and limited to the most essential ones needed to provide a basic solution that a TPD community can apply quickly to become socially operational.

With the exception of the MM-Record component, (discussed in priority 2 below) which was tested during the last series of TATA-BOX workshops in 2017 (cf. Fig. 2), the tools mentioned below were not tested in the project itself. However, since these tools are generic, they have already been tested in other social situations (cf. e.g. Bénel et al. 2010). These experiences with a variety of research fields have made it possible to problematise the notion of a social semantic Web infrastructure platform (Cahier et al. 2013). This social validation work would still have to be carried out on scale one throughout the whole process of implementing the TATABOX method, and would require major ICT developments and arrangements.

\section{Priority 1: A Collaborative Basis for All TATA-BOX Roles and Actors}

According to criteria previously listed (cost, workforce, efficiency, etc.), it is necessary to give priority consideration to the ICT platform as it is used, not only by the "field participants" of rural areas, but also by all other roles necessary to the design methodology. We observed during the TATA-BOX workshops that basic participants' roles are only the tip of the iceberg. 
Reflection on tools must also consider the immersed part as equally important, that is, the roles inter alia of community organisers (managing invitations and staff, meeting agendas, their own agendas, etc.), facilitators, transcribers, observers and analysts (from several scientific disciplines), managers of certain technical tools (video, sound), graphic designers and producers of "rich picture" artefacts (who play a major role in the methodology).

The platform must meet a twofold challenge: to help all these actors to work on content, according to their role in the structure, but without the structure of the roles being prescribed rigidly by software workflows. Therefore, as a matter of priority, the platform requires a foundation of basic community functions, accommodating the different possible roles and supporting their mutual trust and design interactions. This is the prerequisite for access to a first stage of basic services (cf. sections "Priority 2: using topic maps to give access to verbatim records and TPD items" and "Priority 3: making visible and affordable the diversity of the viewpoints") offering all these roles (at least) read-only access to the traces of discussions, whatever their forms (audio, video, text). For example, this will allow everyone in the community to retrieve documents after the fact or in case of absence, and thus stay in touch with the community, one of the great challenges in such community design that spreads over months to years (cf. chapter "Evaluation of the Operationalisation of the TATABOX Process").

In the TATA-BOX method, the many roles give rise to varied interactions. Since TPD requires a complex collaborative design, the interactions between these roles and the objects and arguments under discussion are also complex. They are considered here in semiotic terms as digitisable traces. The challenge for the platform is to assist the creative or manipulative interactions of these contents by the various roles. On one hand they are interactions between actors sharing the same role. Of particular interest, for example, are the "cross-reading" scenarios between participants, in which each participant, rereads a transcribed discussion, highlights critical items, annotates and tags passages in the margins, and interacts with their peers through chained annotations. On the other hand, there are interactions between actors of different roles. For example (cf. Fig. 2) the "secretary" actor responsible for the audio recording of a discussion lasting several hours, annotates (on-the-fly or off-line) the audio stream with tags. These markers will be used: (i) by the transcriber to find his/ her place quickly when he/she listens again; (ii) to construct useful markers for the group; and (iii) to indicate to the transcriber which fragments he/she has to process (this will save time and money in the overall process), etc.

From an IT point of view, this means that the platform must propose an infrastructure of participation architecture facilitating a coherent registration of actors into well-defined roles (Zaher et al. 2007; Merle et al. 2012; Tosi and Bénel 2017). Its basic services must enable the TPD Community on its own to finely regulate functions such as directory and member sponsorship, ${ }^{2}$ role endorsement, role access

\footnotetext{
${ }^{2}$ Open Source tools integrated with the Hypertopic suite (see below and http://hypertopic.org) could be used for these functions, such as AAAforREST and DoLoMite ("Directories Led by Members", to federate digital identities management for multiple CSCW tools).
} 
rights to various possible actions on documents (as in the examples provided above), and so on. Each of the actors thus benefits from prerogatives associated with their role. For example, for everyone there would be commentary rights; for some (managers, experts, etc.), the right to create tags; for other roles, more specific rights of creation or modification of contents (such as the transcribers' right to deposit texts), and so on. This type of basic infrastructure, allowing such fine tuning of access and roles, is not currently available on the shelf. ${ }^{3}$

The analysis of the TATA-BOX method as a socio-technical device needs to be deepened in order to fully explain the roles, their interactions, and the critical passages in the documents. The objective is not that this modelling automatically be translated into numeric terms, but rather that it help to apply the TATA-BOX method by allowing on the platform certain actions and interactions typical of roles, especially the countless TPD items that actors are constantly releasing and re-injecting into the discussion.

\section{Priority 2: Using Topic Maps to Give Access to Verbatim Records and TPD Items}

During the whole process, the TPD community's actors are faced with an intensive flow of changing knowledge and with many difficulties to memorize it, and seek to share numerous documents. The more important ones are the oral and transcribed verbatim recordings of meetings (more than $100 \mathrm{~h}$ of audio and video material were recorded in the TATA-BOX workshops). It is also necessary to share, index and retrieve secondary documents such as analyses, annotations by actors, and so on. ICT can be helpful in giving participants and other roles the best semantic affordances to their practices, especially at the critical stages of the TPD process.

We propose to use a method derived from the "Document and Item-based Modelling" method (Cahier and Ma 2010; Cahier et al. 2010) allowing items of the discussion to be described easily and organised in a NoSQL Web repository. TPD items are items of interest (actual facts, ideas, actors, fictional facts in prospective scenarios, opportunities, etc.) appearing in the collective inquiry on the complex rural situation, when solutions, governance plans, and so on are being devised. These items emerge from discussions and documents and are continuously (re-) interpreted, (re-)evaluated and (re-)used in participant's discussions and plans. The

\footnotetext{
${ }^{3}$ In terms of basic community services, the corresponding functions are usually the functions of invitation, registration or deletion, directories, sponsorship, diary, etc. We do not advise turning these functionalities into packaged solutions (Content Management System - CMS - or Electronic Document Management Image Management System - IMS). Their role structures, stereotyped for common usage, are not appropriate here. In addition, many teleworking, referral or profile functions (see social networking platforms) are also not necessary since the actors are in direct contact through meetings.
} 
proposed ICT Social Semantic Web services on the platform allow items to be described by topics and by valuated attributes (e.g. for the geographical situation of a TPD item), in order to reflect each one's identity, categories and possible associated Web resources. With this method, actors can safely and confidently characterize, name, memorise and share thousands of TPD items.

To facilitate the retrieval of information, we suggest topic cloud and topic map artefacts. They can be constructed collaboratively by using the entire sequence of meetings' verbatim records (audio and video recordings, re-listening, transcription, reading, re-reading, annotation, etc.). With tools proposed to support the "Document and Item-based Modelling" method, actors can easily refer to the documents on their discussions and the annotations made during and after TPD meetings (on maps, on post-it notes, etc.). They can refer to all TPD items, geo-localised or not, as they identify and discuss them continuously ("on the fly") during the TPD process.

Figure 1 shows how items refer to discussed reality and how they rely on the topic map. The right side of the figure, on the cold slope, corresponds to the documents and to the more reified or consensual items shared by the community. The left side, on the warm slope, corresponds to the more emerging items and their more subjective and interpretable aspects, brought up during the TPD collective inquiry. So the "item" concept creates a bridge between the two sides. At a given point in a discussion, a participant may mention a TPD item he/she observed in the rural situation and that made sense to him/her. Even if it has not been stabilized, this item can be created in the repository (path " 3 " in Fig. 1). But items can also be detected in a document (path "2" in Fig. 1). All items can then be constructed in more detail (paths "5", "6", "7") by identifying its proper name and adding attributes (e.g. localisation), topics and resources. If other actors recognise an item as a relevant element of the shared situations, they can qualify it with complementary (or concurrent) attributes and topics, thereby allowing the community to maintain the co-building of the item and the topic map linked to it.

By using TPD items as mediation, the indexing of documents can be facilitated by the actors themselves. Participants can name and characterize well-known items because they are familiar in their all-day skills or in their documents (Fig. 1, path 2). This folksonomy facilitates the use of the verbatim records, reduces actor's puzzlement within verbatims and all the TPD documents, despite the fact that they are numerous, changing, added by multiple contributors ... and frequently controversial (cf. section "Priority 3: making visible and affordable the diversity of the viewpoints").

This approach can be illustrated and implemented by existing prototype tools, such as Argos and Steatite based on REST Web Services, supplemented by the MM-Record tool (Matta and Ducellier 2013) for indexing recorded audio streams from a tablet. These tools will make it possible to implement the proposed method and build up a document base of TPD items easily accessible on the Web from a topic map. 


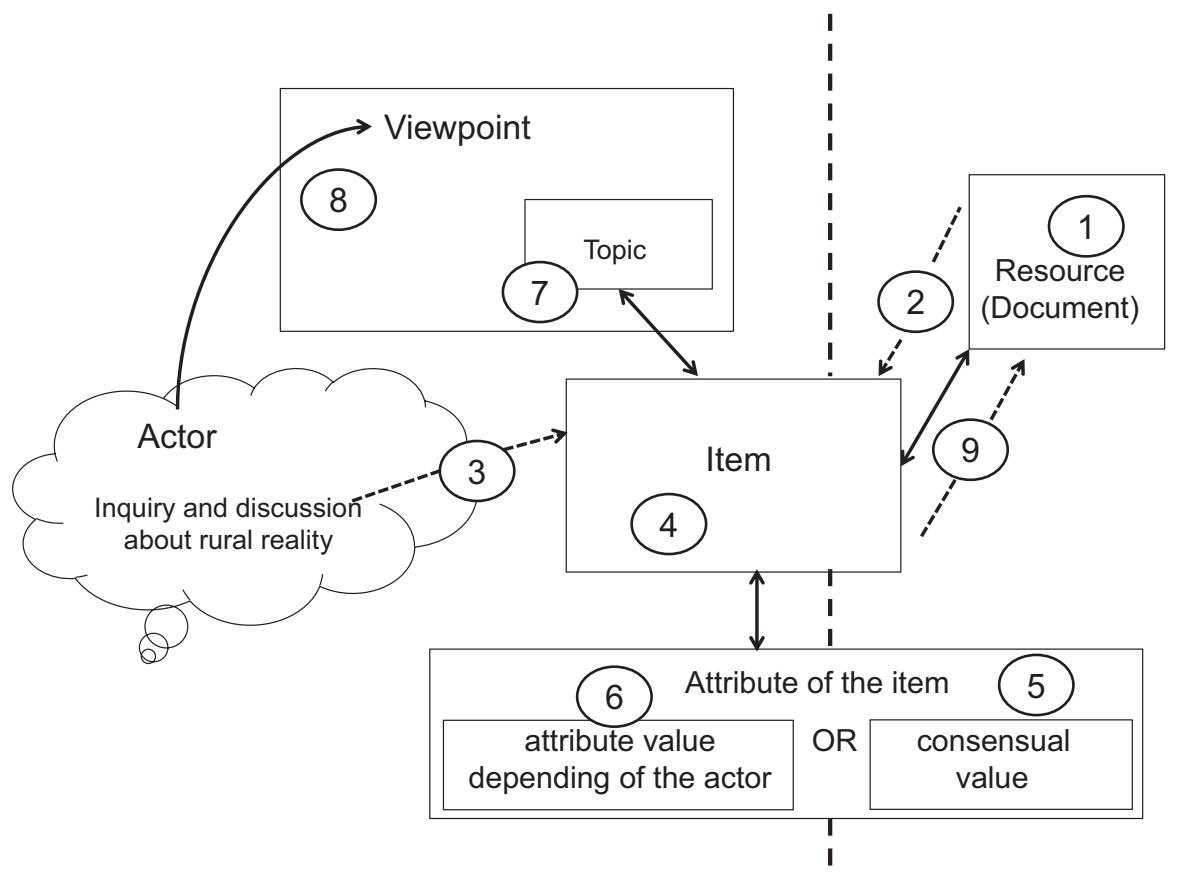

Fig. 1 "Document and Item-based Modelling Method" (using the Hypertopic conceptual frame) applied to TPD collaborative work

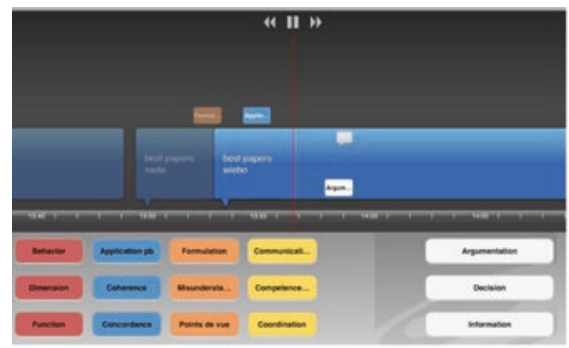

a)

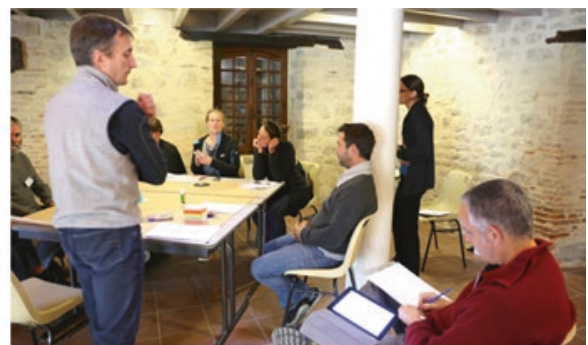

b)

Fig. 2 MM-Record tool on tablet (a) and its use during a 2017 TATA-BOX design meeting (b)

MM-Record (Fig. 2) completes the audio recording of meetings by allowing participants to index the audio content with coloured marks and tags for time, speakers' names, and categories, and to design rationale topics. In the abundant records of the 2017 TATA-BOX meetings (lasting many hours), it helped actors to retrieve 
oral fragments and tag them. The oral material related by participants was shared and socially annotated. In particular, some tags put onto the recorded audio flow were used to select the more relevant fragments to be transcribed, thus reducing the transcription cost.

\section{Priority 3: Making Visible and Affordable the Diversity of the Viewpoints}

One of the key challenges for the platform is to allow the multiple actors to benefit from a multi-viewpoint approach in terms of content categorisation and how to find fragments more easily through a repository that gives meaning to these fragments. This also applies to the primary contents of the design (e.g. traces of the discussions) or derived contents (e.g. annotations, tagging and threads of discussions outside the verbatim records).

Given the specificities of the AET in a given territory, it is important to make visible and integrate the different points of view. To technically implement a multiviewpoints anchorage structure into the content, we propose that the topic maps artefacts mentioned previously (cf. section "priority 2: using topic maps to give access to verbatim records and TPD items"), using the Hypertopic model (Zhou et al. 2006) as a background. The structure of hypertopic actors and viewpoints can be organised to help actors to make traceable and visible the interpretations from their own perspectives (cf. the upper part of Fig. 1: paths 3-4-8-7 and 1-2-4-7-8 for example). Thus, actors can elicit the TPD items and qualify them, not only at a "reference" level (recording consensus when it exists) but also at the heuristic and inter-subjective levels (Bénel et al. 2010), considering that items always stay, to a greater or lesser degree, in design and in debate.

In this way, in order to carry out the necessary tests, we recommend that existing multipoint tools based on the Hypertopic model, such as Argos, Agorae, Porphyry (cf. http://hypertopic.org) that can be used on the Web, be industrialised and extended according to the specific context of TPDs. These tools allow one to build and compare views on the items of the domain. Cassandre and Lasuli, also tools of the Hypertopic suite, can be used by multiple analysts to carry out qualitative analyses of the same corpus, and to compare their categories (Bénel et al. 2011; Lejeune 2011).

Actors may use various views on items in the TPD cooperative work and debate about them. Multi-viewpoint social tagging can be applied with ease by end-users without any knowledge in Information Sciences. It is designed specifically to be used in communities whose members are faced with an intensive flow of changing knowledge and with many difficulties to represent it visually on a topic map, as well as many conflicts between actors, especially conflicts of interpretation. 
Note that this approach does not require a set of predefined viewpoints or categories. On the contrary, it offers freedom in the choice of perspectives from which to interpret and organise information. Depending on the way in which a TPD community decides to use these tools, in particular according to the phases of collaborative design, the points of view can be those of the stakeholders (corresponding to their field of competence, their opinion, etc.). Stakeholders may also participate in games of analysis, the dimensions of which are decided by mutual agreement, such as the game of the three major "structural" dimensions advocated by the TATA-BOX method. Thanks to its underlying Hypertopic model, the proposed platform remains agnostic in semantics and does not influence the daily languages of the actors, whether they are experts or not. This flexibility is important for TPD communities, which can thus, for example, balance the expression of minority actors with that of more powerful stakeholders.

\section{ICT to Support the Implementation of a Territorial Agroecological Transition}

The previous section discussed the possible utility of ICT during the TPD. The present section explores the roles IC tools can play after the design step, when the transition is practically implemented by the actors of a territory. Reix et al. (2016) classify ICT according their use: communication, functional use, knowledge management, and decision-support. The digital technologies that could economically, socially and environmentally support the development of a territorial AET are classified in this section according to this usage typology, with different practical illustrations for each class.

\section{Communication Systems}

Communication technologies facilitate the circulation of data, information and knowledge inside an organization or from an organisation to its targeted public. This includes generic tools such as websites, videoconferencing systems or exchange of digitized data systems (Soulignac 2012).

Communication is essential for all sectors and not only for agriculture. But it is a particularly important stake for agroecology: constructing a territorial transition requires coordination between a wide variety of actors that do not usually communicate but should all be involved for the functional implementation of an agroecological food system. During the TATA-BOX Project, communication was mainly during workshops. In order to maintain and even improve the network dynamic generated during those workshops, digital communication tools should lead up to classic physical meetings during the implementation stage. These tools can notably 


\section{Box 1: A Catalogue of Theoretical and Practical Trainings in Agroecology}

The French platform Osaé (Osons l'agroécologie, in English "Dare agroecology") was developed to foster the implementation of agroecology. It presents farmers' testimonies and technical syntheses, as well as an agenda listing the future agroecology meetings in France, from colloquia to field visits and technique trainings (Osaé 2017).

Link: www.osez-agroecologie.org

help to communicate synchronously or asynchronously, to increase the visibility of the project, to interact with actors that were not identified a priori (Agroecology in Action 2017), to disseminate results of observatories, or to organize "face-to-face" or digital knowledge exchanges (Box 1).

\section{Functional Tools}

Functional technologies include all the applications supporting the processing of recurrent tasks that can easily be digitised. In agriculture, their first applications were accounting tools designed for the economic management of a farm, but they also include commercial support tools (Soulignac 2012).

By enabling almost instantaneous contact between farmers, or between farmers and consumers, functional technologies could support the development of an agroecological food system in at least four ways. First, websites and mobile applications are efficient ways to organise exchanges of agricultural goods such as straw, livestock manure, compost, or even household and communal organic waste (FourrageFWA.be 2017). By exploiting the complementarity of the diverse farming systems present in a territory in terms of inputs and outputs, those exchanges are one of the keys for recycling biomass and minimizing resource losses (Moraine et al. 2016, 2017a, b; Therond et al. 2017, chapter "An Integrated Approach to Livestock Farming Systems' Autonomy to Design and Manage Agroecological Transition at the Farm and Territorial Levels"). Second, the same kind of commercial agricultural websites can facilitate the trade of animal and vegetal (seed) varieties adapted to local/territorial conditions, which is a way to foster genetic diversification and to enhance the value of local resources. Third, organising a sharing system for mechanical material can be facilitated by a digital application (WeFarmUp 2017). This collective practice is a good way to try agroecological alternative practices requiring specific machines at a moderate cost, both economically and environmentally (fewer machines are manufactured). Finally, websites are powerful tools for the construction of re-localised food systems co-managed by both producers and citizen-consumers. The ICT connection between farmers and 


\section{Box 2: "Agrilocal”, a Platform to Connect Local Farmers and Public Authorities}

Developed initially by the General Council and the Chamber of Agriculture of the Drôme and Puy-de-Dôme départements (France) in 2012, Agrilocal is a free website that allows local farmers to directly contact public procurement services with a collective catering mission (schools, hospitals, retirement homes, etc.). The platform shows the buyer all the products that are available locally and that correspond to their needs, and each seller has a personal page to present its farm. Agrilocal is now operational in 24 French départements (Alim'agri 2015).

Link: www.agrilocal.fr

\section{Box 3: Crowdfunding Applied to Agricultural Projects with "BlueBees"}

BlueBees is a participative funding platform dedicated to sustainable agriculture and nutrition projects that are ecological, economically viable and a source of employment and social links (Bluebees 2017). By presenting the projects on the basis of their geographical location, the website helps project leaders to gather a community of contributors that will not only finance their initiative (by lending or giving money) but also probably support its proper functioning once it is launched, for example by buying its products or by participating in consumers' general assemblies.

Link: https://bluebees.fr/

citizens can facilitate both the practical selling process (Box 2) and the financial support for local food production and transformation projects by future consumers (Box 3). This latter website's role is important since a democratic governance of food issues making peasants more autonomous with regard to dominant market forces is a crucial principle in the AET in a territory (Stassart et al. 2012).

\section{Knowledge Management Systems}

Knowledge management (KM) technologies include all the tools that serve to create, stock, disseminate and update knowledge (Soulignac 2012).

The development of an AET fostering a "strong" ecological modernisation of agriculture (Horlings and Marsden 2011) requires the implementation of agricultural practices in favour of agro-biodiversity and ecosystem services at different ecological, spatial and temporal scales (Kremen and Miles 2012; Duru et al. 2015b). 


\section{Box 4: “Geco", a Collaborative Web Tool for Constructing Knowledge in Agroecology}

Geco is a KM web application dedicated to agroecology that was jointly developed by INRA, ACTA and IRSTEA as part of the French Ecophyto plan for pesticide-use reduction in agriculture. The website is divided into two spaces: one is a "knowledge base" enriched collaboratively by contributors from the whole farming community and recognized by their peers. This base presents knowledge in the form of pages classed by concept such as alternative practices, crops, pests, material, pest auxiliaries, etc. The second space is a forum in which anyone can create a discussion topic related to a particular knowledge page or concerning a subject that is not yet treated in the knowledge base. To organize and structure all the information and knowledge available in the base and in the forum, and to enable their effective use during research, the website integrates a semantic model allowing the creation of links between pages (Soulignac et al. 2017). For example, a contributor can define the following relation between concepts by linking pages: the Crop (page) "lentil" - "is attacked by" - the Pest (page) "lentil weevil".

For now, the knowledge base mainly contains pages about innovative agricultural techniques, written by contributors from the inter-technological network "RMT SdCI" (Guichard et al. 2015).

Link: http://geco.ecophytopic.fr/

This implementation can be supported by KM technologies in at least two ways that are described in the next paragraphs.

First, practices combining agricultural production and natural resource management are subject to many uncertainties (Williams 2011; Chapter "A Plurality of Viewpoints Regarding the Uncertainties of the Agroecological Transition"). In order to minimize the risk taken by the farmers adopting those practices, it is crucial to lower their unpredictability. We can distinguish two levels of action for lowering uncertainties: supporting experience-sharing, and creating new knowledge via data analysis.

- Supporting experience-sharing: in recent years, many websites assisting agricultural practitioners in accessing and sharing knowledge about agroecology have emerged. Reflecting the socio-economic principles of agroecology defined by the GIRAF (Stassart et al. 2012), these websites value and disseminate a diversity of forms of knowledge (local know-how, empirical knowledge, etc.), and are sometimes designed to foster networking and debate. The range of technologies they use is fairly wide, since some of them simply bring inexperienced and experienced practitioners into contact with one another (Agricool 2017; Agrifind 2017), while others collect and archive stories of successful agroecological experiences (Farmers2Farmers 2017), or collaboratively capitalize on knowledge about sustainable agriculture (DicoAgroecologie 2017), sometimes with the help of semantic technologies (Box 4). It should be noted that besides 


\section{Box 5: "AGROSYST", Capitalising on Knowledge About Low Pesticide- Consuming Farms}

Developed as a part of the national ECOPHYTO plan, the DEPHY network encompasses more than 2000 farms and experimental sites trying to minimise their dependence on phytosanitary products by modifying their agricultural practices. In order to facilitate the valorisation and transversal analysis of the results obtained with this programme, the information system AGROSYST was developed to collect, store and exploit data from the participating farming systems. The system integrates the following functions: acquisition and hosting of various data (crop rotation, cultivation operations, decision rules, measures and observations, economic margin etc.), calculation of synthesis variables, editing of decision schemes, and interoperability with other information systems (Bournigal 2016).

those websites dedicated to agriculture, generic social networks like Facebook or Twitter are becoming places where farmers gather to informally share their experiences.

- Creating new knowledge via data analysis: so much agricultural data already exist that the technical term "big data" is often used to describe them. These data come from drones, sensors, connected objects, satellite images, traceability and crop management softwares (Box 5), or even biodiversity voluntary surveys and other crowdsourcing practices. They are often characterised by spatial and temporal dimensions (\#DigitAg 2017). In addition to these structured sources, many agricultural unstructured documents contain precious information that can be extracted and homogenised to produce exploitable data, for example through the use of semantic technologies (Box 6). ICTs are used for the creation, transfer, storage, structuring, sharing and finally exploitation of such data. This process can help to better understand the agro-ecosystem thanks to technologies such as machine learning (less understanding but better prediction), visual analytics, data statistical analysis, data mining or integration of imperfect knowledge (\#DigitAg 2017). These advances in the understanding of agricultural phenomena could allow the development of new decision-support tools (Bournigal 2016) that can be more or less near to the principles of agroecology (cf. section "Decision-support systems").

Second, the redesigning of a food system involving agricultural practices that foster agro-biodiversity and ecosystem services needs to be supported by a learning system adapted to the stakeholders. For the past few years, agroecology has been part of the teaching programmes in some agricultural schools (Alim'agri 2016). Master's degrees and certifications in agroecology have been developed throughout Europe (Agroecologie.fr 2017; Certificat-agroecologie 2017; Master-agroecologie 2017). These initiatives are not however sufficient. As vast numbers of people, with 


\section{Box 6: Facilitating Access to the Regional Pest Alert Bulletins via Semantic Technologies}

During the VESPA project, financed by the national ECOPHYTO plan, the institutes INRA and IRSTEA examined the usefulness of the French crop epidemio-surveillance programme. To do so, thousands of regional pest alert bulletins published during the last 50 years were collected and digitised, and an open data platform was created to access them freely. To facilitate the research through this corpus, three classes of semantic annotations were used to describe the content of each document: spatial annotations (the region concerned), temporal annotations (the publication date), and thematic annotations (the principal crop concerned). These annotations can be enriched by the organisations that published the bulletins and supplemented by links to other resources such as weather reports (Roussey et al. 2016). This perennial access point facilitates the observation of spatio-temporal dynamics for epidemiological modelling, and can lead to the identification of locally efficient crop protection practices if other data such as crop diversity or hedge density are available for the same regions and periods (EcophytoPIC 2017).

Link: www.pestobserver.eu

\section{Box 7: The First Massive Open Online Course (MOOC) on Agroecology With the technological support of the French Numerical University (FUN), the Montpellier SupAgro engineering school built a MOOC presenting the different approaches of agroecology. More than 12,000 participants from 100 countries enrolled in the first edition of the course. In a participatory training dynamic supported by the social and geographical diversity of the actors, the MOOC proposes to build an agroecology approach at the interface between agronomic, ecological and social sciences. The course content will be avail- able on the platform under a Creative Commons license (FUN MOOC 2017). \\ Link: https://www.fun-mooc.fr/}

a wide range of profiles in terms of nationality, time availability, profession, etc., are interested in such courses, ICTs are already part of the agroecological education plan. Their original forms are interesting for fostering the construction of innovative teaching methods adapted to the holistic and systemic nature of agroecology (Box 7) (Pollen 2017; Supagro 2017; UVAE 2017). Aside from the interest of their original format, virtual teaching is also a good way to facilitate interactions and knowledge-building between the different scientific disciplines involved in research and teaching in agroecology (Stassart et al. 2012). 


\section{Decision-Support Systems}

Technologies for decision-making are able to process data in order to provide advice. They have several levels of complexity, from simple dashboards presenting data in an organized way, to tools providing clear operation orders according to predetermined objectives and action rules (Soulignac 2012). Decision-support tools are based on two resources: instantaneous data providing information on the present situation, and previous knowledge on which their decision models are built.

Most agricultural decision-support technologies presently concern simple, mono-task operational decisions. They are used in domains such as precision agriculture - the right dose/action, at the right place, at the right time - or pest evolution monitoring. They often reduce the observation and/or action time required from field actors, which is helpful insofar as those activities are generally time-consuming when a new agroecological farming system is implemented. Besides those simple tools, many scientists are already working on decision-support systems that go beyond the mono-task stage, concerning mainly integrated pest management (AGIR 2017), but also other subjects like multi-species meadow design (Box 8). In the future, interdisciplinary research based on the analysis of data available thanks to knowledge management technologies could lead to a better understanding of local agro-ecosystems and of the reaction they can have to global changes in farming systems. This potential acquisition of systemic and contextualised knowledge could open the door to decision-support tools better suited to assist the agroecological redesigning of food systems, for example in the form of a classic (face-to-face) territorial board game in which the players' actions are guided by a software calculating the economic, agronomic, environmental or social impacts of different agricultural and commercial choices (Duru et al. 2015b).

\section{Box 8: "Capflor", an Agroecological Tool for Designing Meadows with Diverse Flora}

Capflor is a free decision-support tool that recommends associations of forage species for meadows, based on soil and climatic conditions and on the intended use of the forage (mowing, grazing or mixed). During a research project called Mélibio, the decision model was constructed both in a multidisciplinary and in a multi-actor way since it synthesised agronomic and ecological criteria and hybridised researchers', advisers' and farmers' knowledge. The INRA team now in charge of the tool has organised a collaborative network with livestock farmers and advisers who give them feedback from the field, thus allowing for a continuous enrichment of the tool. While Capflor is primarily intended for livestock farmers and agricultural advisers, it can also be used as a teaching tool in agricultural schools, to introduce students to multi-species meadows (Capflor 2017).

Link: http://capflor.inra.fr/ 


\section{ICT and Agroecology: What Are the Challenges?}

\section{Research Needs and Development Conditions}

Since July 2017, the French research, teaching and industrial organisations working on digital agriculture have gathered around the \#DigitAg Convergence Institute to design ICT that will effectively be used by the public aimed during the design (that is not always the case), from the acquisition of data to their exploitation (Alim'Agri 2017). To meet its different challenges, which include the development of IC tools of service to the AET (\#DigitAg 2017), the Institute has identified six areas (hereinafter called "axes") in which multidisciplinary research is needed (Table 1). Axes 3-6 correspond to the classic "collecting - organizing - visualizing and mining modelling" chain of digital data technologies, and mainly concern natural sciences and technology. Axes 1 and 2 highlight the social and economic dimensions and the fact that they must not be forgotten if we want to bring ICT research from the lab to the field.

The first axis examines issues about the social and economic impacts of ICT, like "how do ICT technologies contribute to improving farm-level management and territory governance?" and "How do ICT-enabled new services change the role of agricultural actors, including advisory services?" (\#DigitAg 2017). The second axis considers social, legal and management matters such as "How do we build technical and organizational digital innovation that will successfully be adopted by the farmers?" and "How do we address the legal and ethical issues of intellectual property of data and knowledge, and what are their consequences on value share?" (\#DigitAg 2017). All these questions are still to be investigated and no complete answers are currently available, but some elements are already interesting to present concerning IC tools adoption and data ethics.

Table 1 The six main axes organizing the \#DigitAg scientific communities, their objective and the major scientific disciplines they involve (\#DigitAg 2017)

\begin{tabular}{|c|c|c|}
\hline Axes & Objective & Major disciplines \\
\hline 1 & $\begin{array}{l}\text { Understanding ICTs' influence on rural } \\
\text { societies }\end{array}$ & Economics, management, social science \\
\hline 2 & $\begin{array}{l}\text { Building ICT-based innovation: } \\
\text { Technological, social and legal issues }\end{array}$ & Law, social science, management \\
\hline 3 & $\begin{array}{l}\text { Fostering the development of appropriate } \\
\text { sensors and data acquisition systems, } \\
\text { including crowdsourcing }\end{array}$ & $\begin{array}{l}\text { Physics, optical science, electronics, } \\
\text { digital science }\end{array}$ \\
\hline 4 & $\begin{array}{l}\text { Making progress in agricultural information } \\
\text { system design }\end{array}$ & Computer science \\
\hline 5 & $\begin{array}{l}\text { Designing new data-mining methods, } \\
\text { appropriate to agricultural data, to extract } \\
\text { actionable knowledge }\end{array}$ & Data science, computer science \\
\hline 6 & $\begin{array}{l}\text { Exploring new ways for model integration/ } \\
\text { qualification }\end{array}$ & $\begin{array}{l}\text { Agronomy, mathematics, computer } \\
\text { science, artificial intelligence }\end{array}$ \\
\hline
\end{tabular}


The adoption of IC tools by farming communities depends on practical criteria such as profitability, simplicity of use, and efficiency of the designer's communication, and must be analysed with the help of various disciplines like sociology, ergonomics or management (\#DigitAg 2017). For example, an ergonomist and an agronomist (Cerf and Meynard 2006) studied the various uses that farmers and advisers made of fertilisation and pest management decision-support tools. Finding that there was a considerable gap between the use that developers had planned and the way the tools were used on the field, they developed the concept of advisory and information systems (AIS), a "temporal and spatial network of humans and material arrangement which allow information to be developed and disseminated in order to make decisions about local monitoring of agroecological processes". They propose to develop a conception methodology taking AIS into account in order to include the users' creativity and needs in the early stages of the design process, which should ease the IC tool adoption by farming communities. The decision-support tool Capflor (Box 8) is a good example of technology co-conceived with its users and continuously adapting to their needs and practices. In the same vein but concerning knowledge management tools, a French knowledge management Club (Club-gc 2017) developed a set of questionnaires allowing communities to better define their needs concerning knowledge. These questionnaires can be adapted to agricultural communities, and help to answer questions like "what technical knowledge is critical or missing concerning this practice?", "how do we diffuse and validate knowledge in our community?" or "which tools would be the most efficient to learn this particular practice?". These examples of design methods integrating users' behaviour and needs are consistent with the agroecological principles of participatory research and final-users inclusion in research, determined by the interdisciplinary group GIRAF (Stassart et al. 2012).

The question of data availability will also become crucial in the next few years, since all the potential of ICT is based on an access to a substantial number of field references. At present, this access does not seem to be guaranteed: although an abundance of data has already been produced, these data belong to a wide range of actors from both sectors - private (farmers, tractor manufacturers, weather station sellers, etc.) and public (Common Agricultural Policy declarations, experimental farms, etc.) -, and collecting them will be a huge challenge (Bournigal 2016). The collection of agricultural data, even for research purposes, furthermore raises questions about intellectual property, privacy, traceability, and freedom, or even about the monetary value of such data (\#DigitAg 2017). The future of data is already splitting up into several directions. Some companies try to acquire sufficient amounts of data with their own sensors to develop good decision-support tools. Others are starting to buy agricultural data from diverse origins in order to sell them in a worldwide data market (Dawex 2017). The French government is considering the development of a national public portal to collect and store all the agricultural data. The idea will be that suppliers give their data to the governmental data portal, and in exchange they can visualize these data and the data from other suppliers integrated in the portal as maps, statistics etc... And if the government creates decision tools thank to these data, suppliers will have access to these tools too (Bournigal 2016). The co-existence of these different models would lower the scientific value of each of them: the less 
data you have, the further from field reality your models are. However, choosing the most relevant model is really complicated, especially because the various data suppliers can have divergent opinions on the purposes those data should serve, their monetary value, and the public they should be accessible to. For the development of an agroecological system that includes ICT as support tools, rather than as a technocentric model, it will be crucial to construct a transparent governance of data, including field actors as important decision-makers.

\section{In the End, Will ICT Save or Consume Non-renewable Resources?}

This chapter has demonstrated that at a territorial scale, many IC tools can support AET as regards their environmental, social, economic and methodological dimensions, during both the design and the implementation phases. However, these demonstrations never considered the steps existing outside the scope of the farmer or territorial community: the construction of the tool, its maintenance and its recycling or treatment as waste. Whatever ICT is considered (sensor, radar, database, website, software, etc.), those steps have considerable non-virtual costs since they all consume energy and non-renewable resources.

From its beginnings, agroecology has been based on the principle that farming systems should use as little fossil-sourced inputs as possible (Altieri 1995). Applying this principle to local farms by using tools that have the opposite impact in other places does not seem very logical.

If ICT designers do care about the energetic cost of their tools, this mainly impacts the steps where an economy of energy is directly profitable (in terms of time and money) for the final user. For example, the COPAIN team of the IRSTEA institute of Clermont-Ferrand is working on minimising the energetic consumption of agricultural sensors by creating programmes optimising activity time for the acquisition and transmission of data (Irstea 2017). The question of the global energetic and environmental impact of a food system using IC tools is not currently covered and should be researched by scientific teams working on life cycle assessment (LCA). The results of LCA studies could help to distinguish between IC tools that have a positive energetic and/or environmental impact globally, from those with a positive impact for the final user, albeit one that is not significant enough to compensate for the negative impacts of the tools' construction, maintenance and treatment as waste. The generalisation of ICT environmental impact assessment via LCA could stimulate developers to favour criteria like circular economy and energetic sobriety in the design of their own future tools. It is moreover worth noting that life cycle scientists do not only work on environmental criteria; matters of economic and social impacts are more and more often addressed via the concepts of life-cycle costing assessment (LCCA) and social life-cycle assessment (SLCA) (ElsaPact 2017). These disciplines would also allow an interesting approach for evaluating the relevance of using various ICTs in an agroecological food system. 


\section{Conclusion}

ICTs are actually everywhere. As we have seen, these tools can be used in the design of an AET of rural areas: supporting multiple points of view, allowing desynchronised forums or debates, creating topic maps to share knowledge, and so on. However, in this section we have outlined only a few. A lot of work is still necessary to propose functional tools to support these transitions of territorial agroecological system.

Many forums on agroecological systems are available, using Internet either to communicate or to manage knowledge. Sensors are available to provide data on various subsystem elements (plant, soil, pests, etc.) and computer and decision support system tools may help in making better management choices. This digital revolution will require proof of concept, acceptance and training. The role of the social sciences will be fundamental to understand, guide and propose schemes on the use of this new diversity of tools. Therefore, this is not only a digital story but also a human story. The French \#DigitAg research project will integrate this social point of view.

\section{References}

\#DigitAg (2017) \#DigitAg: La Recherche. Online. http://www.hdigitag.fr/fr/la-recherche/. Accessed 22 Sept 2017

AGIR (2017) PEST: Analyse et modélisation des effets des pratiques agricoles sur les pressions biotiques et les dommages induits en grande culture. In INRA - AGIR - Equipe VASCO. https://www6.toulouse.inra.fr/agir/Les-equipes/VASCO/Recherche/PEST. Accessed 26 Sept 2017

Agricool (2017) www.agricool.net: on ne fait plus labour mais on sème toujours. http://www. agricool.net/forum. Accessed 19 Sept 2017

Agrifind (2017) Agrifind: "l'expertise terrain partagée". https://connexion.agrifind.fr/infos/about. Accessed 21 Sept 2017

Agroecologie.fr (2017) Agroécologie: Formations diplômantes. http://www.agroecologie.fr/formation.html. Accessed 22 Sept 2017

Agroecology in Action (2017) Agroecology in action: Carte des initiatives. In Agroecology in Action Online. http://www.agroecologyinaction.be/spip.php?rubrique13. Accessed 19 Sept 2017

Alim'agri (2015) Avec "Agrilocal", mettre en relation producteurs locaux et acheteurs publics. In Alim'agri: site du Ministère de l'Agriculture et de l'Alimentation

Alim'agri (2016) "Faites de l'agro-écologie": des lycées agricoles engagés! In Alim'agri : site du Ministère de l'Agriculture et de l'Alimentation. http://agriculture.gouv.fr/faites-de-lagroecologie-des-lycees-agricoles-engages. Accessed 22 Sept 2017

Alim'Agri (2017) Agriculture numérique: inauguration de l'Institut Convergences \#DigitAg. In Alim'agri : site du Ministère de l'Agriculture et de l'Alimentation. http://agriculture.gouv.fr/ agriculture-numerique-inauguration-de-linst. Accessed 27 Sept 2017

Altieri MA (1995) Agroecology: the science of sustainable agriculture. Westview Press, Boulder

Bénel A, Zhou C, Cahier JP (2010) Beyond web 2.0... And beyond the semantic web. In: Randall D, Salembier P (eds) From CSCW to Web 2.0: European developments in collaborative design, computer supported cooperative work. Springer, London, pp 155-171 
Bénel A, Cahier JP, Tixier M (2011) LaSuli: un outil pour le travail intellectuel. In: Actes du 14e colloque international sur le document électronique (CIDE). Europia

Bergez JE, Soulignac V, Cahier JP, et al (2016) ICT to help on participatory approaches for the agroecological transition of agriculture. In: 12th European IFSA symposium 2016. Harper Adamn University

Bluebees (2017) BlueBees: financing tomorrow's agriculture. https://bluebees.fr/en/. Accessed 18 Sept 2017

Bournigal JM (2016) AgGate: Portail de données pour l'innovation en agriculture. Report for the French Ministries of National Education, Superior Education and Research, of Agriculture, Agri-food Industry and Forest, and of Industrial and Numerical Economy. http://agriculture.gouv.fr/un-portail-de-donnees-pour-linnovation-en-agriculture-la-synthese-du-rapport. Accessed 22 Sept 2017

Cahier JP, Ma X (2010) Document and item-based modeling: a Hybrid Method for Socio-Semantic Web In: Proceedings of the tenth ACM symposium on document engineering (DocEng) ACM, pp 243-246

Cahier JP, Zaher LH, Isoard G (2010) Document et modèle pour l'action, une méthode pour le Web socio-sémantique. Doc numérique, RSTI, Hermès-Lavoisier 13:75-96

Cahier JP, Benel A, Salembier P (2013) Towards a "non-disposable" software infrastructure for participation. Interact Des Archit J - IxD\&A 18:68-83

Cahier JP, Brébion P, Salembier P (2016) Using and supporting explicit viewpoints in territorial participatory design meetings. In: 17th European Conference on Knowledge Management (ECKM 2016), 1 - 2nd September 2016. ACPI, Belfast (UK), pp 136-145

Capflor (2017) Capflor: outil agroécologique d'aide à la conception de prairie à flore variée. http:// capflor.inra.fr/. Accessed 27 Sept 2017

Cerf M, Meynard JM (2006) Les outils de pilotage des cultures: diversité de leurs usages et enseignements pour leur conception. Natures Sci Sociétés 14:19-29

Certificat-agroecologie (2017) Certificat en agro-écologie et transition vers des systèmes alimentaires durables: une formation continuée inter-universitaire. http://nmktebld.preview.infomaniak.website/. Accessed 22 Sept 2017

Club-gc (2017) Club Gestion des Connaissances. http://www.club-gc.asso.fr/. Accessed 28 Sept 2017

Dawex (2017) Agriculture. In Dawex: la place de marché pour monétiser et acquérir des données. https://www.dawex.com/fr/industries/agriculture/. Accessed 28 Sept 2017

DicoAgroecologie (2017) Dictionnaire d'agroécologie. http://dicoagroecologie.fr/. Accessed 9 Nov 2017

Duru M, Therond O, Fares M (2015a) Designing agroecological transitions; a review. Agron Sustain Dev 35:1237-1257. https://doi.org/10.1007/s13593-015-0318-x

Duru M, Therond O, Martin G et al (2015b) How to implement biodiversity-based agriculture to enhance ecosystem services: a review. Agron Sustain Dev 35:1259-1281. https://doi. org/10.1007/s13593-015-0306-1

EcophytoPIC (2017) VESPA: Valeur et optimisation des dispositifs d'épidémiosurveillance dans une stratégie durable de protection des cultures. In EcophytoPIC: Le portail de la protection intégrée des cultures. http://www.ecophytopic.fr/tr/innovation-en-marche/ecophyto-recherche/ vespa-valeur-et-optimisation-des-dispositifs-d. Accessed 26 Sept 2017

ElsaPact (2017) ELSA PACT: Chaire industrielle en évaluation de la durabilité du cycle de vie. http://www.elsa-pact.fr/language/fr/. Accessed 29 Sept 2017

Farmers2Farmers (2017) Farmers2Farmers, Greenpeace. https://fr.farmers2farmers.org/. Accessed 21 Sept 2017

FourrageFWA.be (2017) FourrageFWA.be: Rechercher votre fourrage en Wallonie. http://fourrage.fwa.be/. Accessed 19 Sept 2017

FUN MOOC (2017) FUN MOOC: Montpellier SupAgro, Agroécologie. https://www.fun-mooc.fr/ courses/Agreenium/66001S02/session02/about. Accessed 21 Sept 2017 
Guichard L, Ballot R, Halska J et al (2015) AgroPEPS, un outil web collaboratif de gestion des connaissances pour Produire, Echanger, Pratiquer, S'informer sur les systèmes de culture durables. Innov Agron 43:83-94

Herrmann T, Jahnke I, Loser KU (2004) The role concept as a basis for designing community systems. In: Proceedings COOP '04, 6th international conference on the design of cooperative systems, May 11-14, 2004,. Hyères, France, pp 163-178

Horlings LG, Marsden TK (2011) Towards the real green revolution? Exploring the conceptual dimension of a new ecological modernisation of agriculture that could "feed the world.". Glob Environ Chang 21:441-452. https://doi.org/10.1016/j.gloenvcha.2011.01.004

Irstea (2017) Projets de recherche nationaux - Equipe COPAIN. In Irstea: Institut national de recherche en sciences et technologies pour l'environnement et l'agriculture. http://www. irstea.fr/la-recherche/unites-de-recherche/tscf/systemes-information-communicants-agri-environnementaux/projets-nationaux. Accessed 28 Sept 2017

Kremen C, Miles A (2012) Ecosystem services in biologically diversified versus conventional farming systems: benefits, externalities, and trade-offs. Ecol Soc 17:25. https://doi.org/10.5751/ ES-05035-170440

Lejeune C (2011) An illustration of the benefits of Cassandre for qualitative analysis. Forum Qual Sozialforsch $=$ Forum Qual Soc Res [FQS] 12:19. https://doi.org/10.17169/12.1.1513

Master-agroecologie (2017) Master interuniversitaire en Agroécologie. http://www.master-agroecologie.eu/. Accessed 22 Sept 2017

Matta N, Ducellier G (2013) Memory meetings : approach to keep track of project knowledge in design. In: 5th international conference on knowledge management and information sharing (IC3K/KMIS). p 12

Merle F, Bénel A, Doyen G, Gaïti D (2012) Decentralized documents authoring system for decentralized teamwork: matching architecture with organizational structure. In: Proceedings of the 17th international conference on supporting group work (ACM GROUP). pp 117-120

Moraine M, Grimaldi J, Murgue C et al (2016) Co-design and assessment of cropping systems for developing crop-livestock integration at the territory level. Agric Syst 147:87-97. https://doi. org/10.1016/j.agsy.2016.06.002

Moraine M, Duru M, Therond O (2017a) A social-ecological framework for analyzing and designing integrated crop-livestock systems from farm to territory levels. Renewable Agric Food Syst 32:43-56. https://doi.org/10.1017/S1742170515000526

Moraine M, Melac P, Ryschawy J et al (2017b) Participatory design and integrated assessment of collective crop-livestock organic systems. Ecol Indic 72:340-351

Osaé (2017) Osaé, osez l'agroécologie: platerforme d'échanges pour la mise en pratique de l'agroécologie. http://www.osez-agroecologie.org/. Accessed 19 Sept 2017

Pollen (2017) Tour du monde Agro-écologie. In Pollen: Le partage des innovations pédagogiques de l'enseignement agricole. http://pollen.chlorofil.fr/documentation/tours-du-monde-agroecologie/. Accessed 21 Sept 2017

Reix R, Fallery B, Kalika M, Rowe F (2016) Systèmes d'information et management. Vuibert, France

Roussey C, Bernard S, Pinet P, et al (2016) Gestion sémantique des bulletins de santé du végétal dans le projet Vespa. Atelier IN-OVIVE @ IC 2016, 12 p.,. In: IC2016: 27es Journées francophones d'Ingénierie des Connaissances, Jun 2016. Montpellier, France

Soulignac V (2012) Un système informatique de capitalisation des connaissances et d'innovation pour la conception et le pilotage de systèmes de culture durables. doctoral thesis, Ecole Doctorale Sciences pour l'Ingénieur, Université Blaise Pascal, Clermont-Ferrand

Soulignac V, Pinet F, Lambert E, et al (2017) GECO, the French web-based application for knowledge management in agroecology. Elsevier Comput Electron Agric 29

Stassart PM, Baret P, Grégoire JC, et al (2012) L'agroécologie : trajectoire et potentiel. Pour une transition vers des systèmes alimentaires durables. In: Van Dam D, Nizet J, Stassart PM (eds) Agroécologie: Entre pratiques et sciences sociales, Educagri E. France, pp 25-51 
Supagro (2017) PARMI: Promoting AgRoecology deMands Innovation in education. http://www. supagro.fr/ferme_wiki/wikis/Parmi/wakka.php?wiki=PagePrincipale. Accessed 22 Sept 2017

Therond O, Duru M, Roger-Estrade J, Richard G (2017) A new analytical framework of farming system and agriculture model diversities. A review. Agron Sustain Dev 37:21. https://doi. org/10.1007/s13593-017-0429-7

Tosi L, Bénel A (2017) Authenticity in a digital era. In: Proceedings of the 2017 ACM symposium on document engineering - DocEng '17. ACM Press, New York, New York, USA, pp 109-112

UVAE (2017) UVAE: Université Virtuelle d’Agroécologie. http://www6.inra.fr/uvae. Accessed 21 Sept 2017

Warner JF (2006) More sustainable participation? Multi-stakeholder platforms for integrated catchment management. Int J Water Resour Dev 22:15-35. https://doi. org/10.1080/07900620500404992

WeFarmUp (2017) WeFarmUp: Louez un matériel agricole maintenant! https://www.wefarmup. com/fr/. Accessed 19 Sept 2017

Wenger E (1998) Communities of practice: learning, meaning, and identity. Cambridge University Press, Cambridge

Williams BK (2011) Adaptive management of natural resources-framework and issues. J Environ Manag 92:1346-1353. https://doi.org/10.1016/j.jenvman.2010.10.041

Zacklad M (2005) Innovation et création de valeur dans les communautés d'action : les transactions communicationnelles symboliques. In: Entre connaissance et organisation\&nbsp: l'activité collective. La Découverte, Paris, pp 285-305

Zaher L, Bénel A, Cahier JP, et al (2007) Digital identities and management of identifiers for a socio-semantic web. In: Proceedings of the 4th international conference on sciences of electronics, Technologies of Information an Telecommunication, SETIT. pp 1-9

Zhou C, Lejeune C, Bénel A (2006) Towards a standard protocol for community-driven organizations of knowledge. In: Proceedings of the 13th international conference on concurrent engineering (ISPE CE'06). IOS Press, p 12

Open Access This chapter is licensed under the terms of the Creative Commons Attribution 4.0 International License (http://creativecommons.org/licenses/by/4.0/), which permits use, sharing, adaptation, distribution and reproduction in any medium or format, as long as you give appropriate credit to the original author(s) and the source, provide a link to the Creative Commons licence and indicate if changes were made.

The images or other third party material in this chapter are included in the chapter's Creative Commons licence, unless indicated otherwise in a credit line to the material. If material is not included in the chapter's Creative Commons licence and your intended use is not permitted by statutory regulation or exceeds the permitted use, you will need to obtain permission directly from the copyright holder.

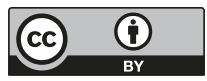

